\title{
Prospective diary survey of preschool children's social contact patterns: A pilot study
}

\author{
Hyang Soon $\mathrm{Oh}^{1}$, Mikyung Ryu ${ }^{2}$ \\ ${ }^{1}$ Associate Professor, Department of Nursing, College of Life Science and Natural Resources, Sunchon National University, Suncheon; \\ ${ }^{2}$ Assistant Professor, Department of Nursing, Daegu University, Daegu, Korea
}

Purpose: This pilot study aimed to describe children's social contact patterns and to analyze factors related to their social contacts. Methods: The participants were 30 children aged $\geq 13$ months to $<7$ years, whose teachers at childcare centers and parents at home were asked to maintain diaries of their social contacts prospectively for 24 hours. Data were collected from November 30, 2018, to January 7, 2019. Results: The 30 participating children were in contact with 363 persons in a 24-hours period (mean, 12.1 \pm 9.1 ). The number of contacts showed significant relationships with day of the week $(p<.001)$, number of family members/cohabitants $(p=.015)$, area of residence $(p=.003)$, and type of housing $(p=.002)$. A multiple regression model showed significantly higher numbers of contacts on weekdays $(\mathrm{B}=10.64, p=.010)$. Physical versus non-physical types of contact showed significant differences in terms of duration, location, and frequency $(p<.001)$. The duration of contacts showed significant relationships with their location and frequency $(p<.001)$, while the frequency of contacts was significantly related to their location $(p<.001)$. Conclusion: This is the first survey describing the characteristics of Korean preschool children's social contacts. Further large-scale social contact studies of children should be conducted.

Key words: Child; Cross-infection; Social distance; Disease transmission, infectious; Contact tracing

\section{Corresponding author Mikyung Ryu \\ https://orcid.org/0000-0002-9915-3175}

Department of Nursing, Daegu University,

33 Seongdang-ro, 50-gil, Nam-gu, Daegu 42400, Korea

TEL +82-53-650-8388 FAX +82-53-650-8389

E-MAIL ryumk@daegu.ac.kr

*This study was supported by the research fund of Korea Centers for Disease Control and Prevention in 2018 (2018E1403000).

Received Jul 11, 2020 Revised Aug 24, 2020 Accepted Sep 19, 2020 (a) This is an Open Access article distributed under the terms of the Creative Commons Attribution NonCommercial License (http://creativecommons.org/licenses/by-nc/4.0/) which permits unrestricted noncommercial use, distribution, and reproduction in any medium, provided the original work is properly cited.

\section{INTRODUCTION}

\section{Need for Study}

Despite the development of antibiotics and revolutionary advances in medical technology, an array of infectious diseases still pose a threat to public health, not only by inducing complications and death, but also by escalating the length of hospital stay and healthcare costs. Infectious diseases are transmitted among people through social contact [1]. In 2015, there was an outbreak of Middle East respiratory syndrome (MERS) in the Republic of Korea (hereafter, Korea). From the first case on May 20, 2015, to the official declaration of the cessation of MERS on December 23, 2015, a total of 186 cases occurred; death occurred in 38 cases (mortality rate, $20.4 \%$ ), and 16,693 exposures were isolated [2,3]. This MERS outbreak spread predominantly through person-to-person contact, and it was quite costly to Korea.

Korea is vulnerable to the spread of emerging infectious diseases, such as MERS and severe acute respiratory syndrome (SARS), because of its high population density, global business expansion, and increased air travel. The earliest historical record of the practice of social distancing was in the Bible [4], and it was enforced in 1377 to prevent the spread of 
the plague pandemic in the port city of Ragusa (now Dubrovnik, Croatia) [5]. Hence, social distancing is the oldest means to prevent person-to-person transmission of disease in the history of mankind. In particular, infectious respiratory diseases can be transmitted from one person to another via physical contact involving direct skin-to-skin contact, such as handshaking, as well as through non-physical contact, such as talking within a 1-2 meter distance, which allows droplet transmission without skin contact $[1,6]$. Therefore, examining the frequency and type of social contact as a modality of infection transmission is crucial for predicting and assessing the effects of infection-preventive efforts. Several nations around the world, including France [7], seven other European Union (EU) countries [1,8,9], Russia [10], Japan [11], and Hong Kong [6], are conducting national- level research on social contact. The findings of social contact studies have served as evidence for predicting the onset of infections or the extent of person-to-person transmission, as well as for developing and deploying various prevention measures, such as selecting targets for vaccination and implementing social distancing measures during outbreaks of infections (e.g., school closures, traveling restrictions, and tracing) [7-9].

According to previous studies $[1,6,7]$, children exhibit unique social contact patterns, such as a higher number of daily contacts than adults $[1,6,7]$. These interactions differ across specific age groups $[1,7]$, and they involve strong assortative mixing, particularly within the same age group [1]. In addition, children have a higher frequency of contact with grandparents [6]. During the recent SARS pandemic and the MERS outbreak, children showed less clinical illness than adults with multiple underlying diseases. The primary threat was that asymptomatic children might transmit the virus to vulnerable adults $[6,12]$.

Early social interactions with caregivers of children are particularly beneficial for childhood development and social competence, including increased cognitive ability, good mental health, communication skills, independence and improved physical health, especially in young children [13]. In contrast, children residing in institutions that provided minimal caregiver-child interactions displayed delayed physical, cognitive, and social-emotional development [14]. Despite the many advantages of social contacts for children, the social contact patterns of children may pose concerns regarding infection transmission $[12,15,16]$.

Until now, social contacts of children have rarely been considered as a means of infection transmission. In particular, during epidemics, children are considered to be an at-risk group because their immune systems are immature compared to adults. Moreover, once infected, there is a higher likelihood that they will transmit the infection to others $[15,16]$.
However, no studies on children's social contacts had been conducted in Korea until 2018, despite the need for a survey on Korean children's current social contact patterns to develop effective transmission prevention measures for them. Therefore, examining the social contact patterns of children, who are at a high risk for infection, is a pressing topic of research since various novel epidemics, such as SARS and MERS, have occurred since 2000.

\section{Purpose}

This is the first pilot study in Korea that aims to present evidence and foundational data for establishing effective infection transmission prevention measures and nationwide studies on social contacts among children, who are considered to be a high-risk group in terms of infection transmission. The specific objectives were to describe children's social contact patterns and to identify the predictors of children's social contacts.

\section{METHODS}

\section{Study Design}

This was a pilot cross-sectional study examining children's social contact patterns.

\section{Study Population}

The target population included children who were capable of verbal communication and were attending a childcare center at which contact transmission could occur. For the convenience of data collection, preschool children aged between 13 months and 84 months attending a group-care facility, such as daycare, were selected. In addition, for contact patterns at home, only children who could be observed by their parents at home were selected. To ensure the accuracy of the contact pattern data, children who were incapable of natural communication or whose contact patterns at home could not be observed by their parents were excluded. Because children are minors and vulnerable, they were enrolled only from childcare centers where the directors voluntarily consented and decided to participate in the study, and if their caregivers (the in-charge teacher) voluntarily provided consent to participate after being informed of the study's purpose and methods. Thirty children (10 each from two childcare centers in Seoul and one in Gyeonggi Province) were enrolled in the study.

\section{Study Instruments}

Through a comprehensive search using key terms, such as 
newborn, infant, toddler, child, and adolescent [17], the existing Social Contact Survey Instrument [18] identified the following five items: 1) number of family members/cohabitants (nominal scale); 2) area of residence (nominal scale); 3) age, sex, and relationship of family members/cohabitants, excluding the child (nominal scale); 4) contact-related information such as sex, age, occupation, physical or non-physical type of contact (nominal scale), duration of contact ( $<5$ minutes, 5-14 minutes, 15-59 minutes, 1-4 hours, and $>4$ hours) (ordinal scale), location of contact (home, childcare center, private academy, transportation, and other) (nominal scale), and frequency of contact (how often they come in contact with this person in general: daily or almost daily, 1-2 times a week, 1-2 times a month, never met before) (ordinal scale); and 5) an open-ended item to check for any missing records in the contact $\log$ and to record additional contact data not addressed in item number 4. A two-round Delphi survey was used to validate the instrument's validity based on a minimum content validity ratio (CVR) > .42 across 20 expert participants, as proposed by Lawshe [19]. Since the CVR value reflects the importance and feasibility of an item, to improve the feasibility of item 4, examples and relevant images of common physical and non-physical types of contact that children routinely experience were also used in the pilot study after they were verified by parents and teachers.

\section{Definition of Contact}

In terms of types of contact, physical contact was defined as direct skin-to-skin contact (e.g., shaking hands, hugging, or kissing with the caregiver or friends), while non-physical contact was defined as engaging in a conversation of at least 2-3 words and keeping a distance of 1-2 meters from the other person (excluding nonverbal exchanges or short one-word conversations) $[1,6]$.

\section{Data Collection}

At each participating facility, parents who had consented to participate were given an in-person explanation about the study's purpose and data collection method and were familiarized with the method for completing the Social Contact Survey Instrument, which was followed by a question-andanswer session to ensure that they had adequately understood. The study participants were instructed to record social contact over any 24-hour period they chose (e.g., 5 AM to 5 AM). They were instructed to explain any physical and non-physical contact through specific examples and to use leaflets with pictures that were tailored to help the children understand the terminology used in the contact diary. Train- ing on the use of the Social Contact Survey Instrument was also imparted to the childcare teachers and followed by a question-and-answer session to ensure their thorough understanding. Parents recorded the type of social contacts that occurred at home and in transportation, and the teacher in charge recorded interactions at the childcare center. The data were collected from November 30, 2018, to January 7, 2019.

\section{Data Analysis}

Descriptive statistics, including frequency and distribution, were analyzed using SPSS 24 (IBM Corp., Armonk, NY, USA). Nominal variables were analyzed using the $x^{2}$ test (Fisher exact test), whereas continuous variables were analyzed using the t-test and analysis of variance. Predictors of children's number of contacts were analyzed using stepwise multiple regression analysis. The relationship between the ages of the children and their contacts was analyzed using a scatter plot in R 3.3.3 (version 3.15) software [20] with the gplots package [21].

\section{Ethical Considerations}

This pilot study of social contacts was approved by an institutional review board (IRB 1040173-201809-HR-026-04). In addition, voluntary informed consent was obtained from participants who showed interest in participating in the study. Before obtaining voluntary consent, the participants were informed of the study purpose, methods, anticipated benefits and risks of participation, and their freedom to discontinue participation and withdraw their consent at any time.

\section{RESULTS}

\section{Social Contact Patterns}

\section{1) Demographic findings of the participants and parents}

Approximately $70.0 \%$ of the children were aged above 36 months and below 60 months, and $56.7 \%$ were males. In $96.7 \%$ of cases, the child's mother was the survey respondent, and the parents' mean age was 37.0 \pm 3.7 years. The study's 30 participants had been in contact with a total of 363 persons in a 24-hour period (mean, 12.1 \pm 9.1 ), and their number of contacts varied according to the day of the week $(\mathrm{t}=4.30, p<.001)$, number of cohabitants $(t=2.20, p=.015)$, area of residence $(t=3.57$, $p=.003)$, and housing type $(\mathrm{t}=3.47, p=.002)$ (Table 1$)$.

2) Characteristics of contacts based on the children's age groups

Approximately $60 \%$ of the contacts of children aged 13-36 months were with family members, while contacts with child- 
Table 1. Demographic Findings of the Participants and Parents $(N=30)$

\begin{tabular}{|c|c|c|c|c|c|}
\hline \multirow[t]{2}{*}{ Variables } & \multirow[t]{2}{*}{ Categories } & \multirow[t]{2}{*}{$\mathrm{n}(\%)$ or $\mathrm{M} \pm \mathrm{SD}$} & $\begin{array}{c}\text { Total contacts } \\
\text { per day }\left(\mathrm{n}^{*}=363\right)\end{array}$ & \multirow[t]{2}{*}{$t$ or $F$} & \multirow[t]{2}{*}{$p$} \\
\hline & & & $\mathrm{M} \pm \mathrm{SD}$ & & \\
\hline Total & & $30(100.0)$ & $12.1 \pm 9.1$ & & \\
\hline Ages of children (month) & $\begin{array}{l}\geq 13 \& \leq 36 \\
>36 \& \leq 60 \\
>60 \& \leq 84\end{array}$ & $\begin{array}{c}53.1 \pm 13.7 \\
3(10.0) \\
21(70.0) \\
6(20.0)\end{array}$ & $\begin{array}{c}5.3 \pm 3.1 \\
11.2 \pm 7.0 \\
15.7 \pm 16.2\end{array}$ & $1.29^{\dagger}$ & .292 \\
\hline $\begin{array}{l}\text { Two groups of children's age } \\
\text { (month) }\end{array}$ & $\begin{array}{l}\leq 48 \\
>48\end{array}$ & $\begin{array}{l}10(33.3) \\
20(66.7)\end{array}$ & $\begin{array}{c}9.0 \pm 5.1 \\
13.7 \pm 10.3\end{array}$ & 1.65 & .109 \\
\hline Children's sex & $\begin{array}{l}\text { Male } \\
\text { Female }\end{array}$ & $\begin{array}{l}17(56.7) \\
13(43.3)\end{array}$ & $\begin{array}{l}12.6 \pm 9.7 \\
10.2 \pm 9.0\end{array}$ & 0.70 & .488 \\
\hline Day of the week & $\begin{array}{l}\text { Weekdays } \\
\text { Weekends }\end{array}$ & $\begin{array}{l}14(46.7) \\
16(53.3)\end{array}$ & $\begin{array}{c}17.7 \pm 10.2 \\
6.1 \pm 3.3\end{array}$ & 4.30 & $<.001$ \\
\hline Number of cohabitants & $\begin{array}{l}\leq 3 \\
\geq 4\end{array}$ & $\begin{array}{l}3.7 \pm 0.7 \\
11(36.7) \\
19(63.3)\end{array}$ & $\begin{array}{c}6.9 \pm 5.0 \\
14.2 \pm 10.3\end{array}$ & 2.20 & .015 \\
\hline Area of residence ${ }^{\ddagger}$ & $\begin{array}{l}\text { Seoul } \\
\text { Gyeonggi Province }\end{array}$ & $\begin{array}{l}16(53.3) \\
14(46.7)\end{array}$ & $\begin{array}{c}6.6 \pm 3.9 \\
17.2 \pm 10.6\end{array}$ & 3.57 & .003 \\
\hline Housing type & $\begin{array}{l}\text { Private house } \\
\text { Apartment }\end{array}$ & $\begin{array}{r}8(26.7) \\
22(73.3)\end{array}$ & $\begin{array}{c}5.8 \pm 2.1 \\
13.7 \pm 10.1\end{array}$ & 3.47 & .002 \\
\hline \multicolumn{6}{|l|}{ Details of children's parents ${ }^{\S}$} \\
\hline Age (year) & $\begin{array}{l}25-39 \\
40-49\end{array}$ & $\begin{array}{r}37.0 \pm 3.7 \\
21(70.0) \\
9(30.0)\end{array}$ & $\begin{array}{l}11.7 \pm 9.4 \\
13.1 \pm 8.9\end{array}$ & 0.39 & 698 \\
\hline Education & $\begin{array}{l}\text { High school } \\
\text { College/university } \\
\text { Graduate school }\end{array}$ & $\begin{aligned} & 2(6.7) \\
22 & (73.3) \\
6 & (20.0)\end{aligned}$ & $\begin{array}{l}25.5 \pm 13.4 \\
10.6 \pm 8.8 \\
10.5 \pm 7.7\end{array}$ & $2.68^{*}$ & .087 \\
\hline Occupation & $\begin{array}{l}\text { No } \\
\text { Yes }\end{array}$ & $\begin{array}{l}18(60.0) \\
12(40.0)\end{array}$ & $\begin{array}{l}12.2 \pm 10.7 \\
10.6 \pm 7.1\end{array}$ & 0.45 & .288 \\
\hline Type of work & $\begin{array}{l}\text { Permanent employee } \\
\text { Part-time work } \\
\text { Unemployed, including housewife }\end{array}$ & $\begin{array}{r}8(26.7) \\
4(13.3) \\
18(60.0)\end{array}$ & $\begin{array}{c}9.5 \pm 5.8 \\
12.8 \pm 9.7 \\
12.2 \pm 10.7\end{array}$ & $0.55^{*}$ & .478 \\
\hline $\begin{array}{l}\text { Personal income/month } \\
\text { (Korean won) })^{\|}\end{array}$ & $\begin{array}{l}\leq 2 \text { million } \\
>2 \text { million }\end{array}$ & $\begin{array}{l}12(52.2) \\
11(47.8)\end{array}$ & $\begin{array}{l}11.7 \pm 7.7 \\
12.1 \pm 9.1\end{array}$ & 0.12 & .906 \\
\hline $\begin{array}{l}\text { Household income/month } \\
\text { (Korean won) }\end{array}$ & $\begin{array}{l}\leq 4 \text { million } \\
>4 \text { million }\end{array}$ & $\begin{array}{l}15(50.0) \\
15(50.0)\end{array}$ & $\begin{array}{l}11.7 \pm 8.6 \\
12.6 \pm 9.9\end{array}$ & 0.26 & .800 \\
\hline
\end{tabular}

${ }^{*}$ Contacts $\mathrm{n} ;{ }^{\dagger}$ Calculated by Fisher's exact test; ${ }^{\dagger}$ Participants were recruited from three childcare centers (two in Seoul and one in Gyeonggi Province), but some participants' residential areas were different from those where the childcare center was located; §The participating parents were 29 mothers and one father. "There were seven participants with missing data, and the t-test was calculated with the exclusion of missing values.

care center staff comprised $37.2 \%$ and $46.2 \%$ of contacts in those aged above 36 months and below 60 months and above 60 months and below 84 months, respectively. While physical contact was the most common type of contact in all three age groups, it accounted for $92.0 \%$ in the children aged 13-36 months. The most common duration of contact was $>4$ hours in children aged 13-36 months (56.0\%), 15-59 minutes in children aged above 36 months and below 60 months (32.0\%), and $<5$ minutes in children aged above 60 months and below 84 months $(33.7 \%)$. The most common location for contact was home $(60.0 \%)$ in children aged $13-36$ months and the childcare center in children aged above 36 months and below 60 months 
Table 2. Characteristics of Contacts Based on the Children's Age Groups $(N=30)$

\begin{tabular}{|c|c|c|c|c|c|c|c|}
\hline \multirow{3}{*}{ Characteristics } & \multirow{3}{*}{ Categories } & \multirow{3}{*}{$\begin{array}{l}\text { Contacts } \\
\mathrm{n}(\%)^{*}\end{array}$} & \multicolumn{3}{|c|}{ Age groups of child participants (month) } & \multirow{3}{*}{$x^{2}$} & \multirow{3}{*}{$p$} \\
\hline & & & $\begin{array}{c}\geq 13 \& \leq 36 \\
(n=6)\end{array}$ & $\begin{array}{c}>36 \& \leq 60 \\
(n=21)\end{array}$ & $\begin{array}{c}>60 \& \leq 84 \\
(n=3)\end{array}$ & & \\
\hline & & & $\mathrm{n}(\%)^{*}$ & $\mathrm{n}(\%)^{*}$ & $\mathrm{n}(\%)^{*}$ & & \\
\hline \multirow[t]{2}{*}{ Sex } & Male & $183(50.4)$ & $11(44.0)$ & $126(53.8)$ & $46(44.2)$ & \multirow[t]{2}{*}{3.11} & \multirow[t]{2}{*}{.212} \\
\hline & Female & $180(49.6)$ & $14(56.0)$ & $108(46.2)$ & $58(55.8)$ & & \\
\hline \multirow[t]{4}{*}{ Member } & Family & $101(27.8)$ & $15(60.0)$ & $62(26.5)$ & $24(23.1)$ & \multirow[t]{4}{*}{$25.79^{\ddagger}$} & \multirow[t]{4}{*}{$<.001$} \\
\hline & Childcare center $^{\dagger}$ & $135(37.2)$ & $0(0.0)$ & $87(37.2)$ & $48(46.2)$ & & \\
\hline & Learning institutions & $36(9.9)$ & $1(4.0)$ & $23(9.8)$ & $12(11.5)$ & & \\
\hline & Others (hospital, etc.) & $91(25.1)$ & $9(36.0)$ & $62(26.5)$ & $20(19.2)$ & & \\
\hline \multirow[t]{2}{*}{ Type of contact } & Physical & $227(62.5)$ & $23(92.0)$ & $138(59.0)$ & $66(63.5)$ & \multirow[t]{2}{*}{10.57} & \multirow[t]{2}{*}{.005} \\
\hline & Non-physical & $136(37.5)$ & $2(8.0)$ & $96(41.0)$ & $38(36.5)$ & & \\
\hline \multirow{5}{*}{$\begin{array}{l}\text { Duration of } \\
\text { contact }\end{array}$} & $<5$ minutes & $76(20.9)$ & $1(4.0)$ & $40(17.1)$ & $35(33.7)$ & \multirow[t]{5}{*}{$46.93^{\text {申 }}$} & \multirow[t]{5}{*}{$<.001$} \\
\hline & 5-14 minutes & $59(16.3)$ & $2(8.0)$ & $34(14.5)$ & $23(22.1)$ & & \\
\hline & $15-59$ minutes & $97(26.7)$ & $1(4.0)$ & $75(32.0)$ & $21(20.2)$ & & \\
\hline & 1-4 hours & $50(13.8)$ & $7(28.0)$ & $35(15.0)$ & $8(7.7)$ & & \\
\hline & $>4$ hours & $81(22.3)$ & $14(56.0)$ & $50(21.4)$ & $17(16.3)$ & & \\
\hline \multirow{5}{*}{$\begin{array}{l}\text { Location of } \\
\text { contact }\end{array}$} & Home & $98(27.0)$ & $15(60.0)$ & $61(26.1)$ & $22(21.2)$ & \multirow[t]{5}{*}{$35.18^{\ddagger}$} & \multirow[t]{5}{*}{$<.001$} \\
\hline & Childcare center & $138(38.0)$ & $0(0.0)$ & $88(37.6)$ & $50(48.1)$ & & \\
\hline & Learning institutions & $34(9.4)$ & $0(0.0)$ & $22(9.4)$ & $12(11.5)$ & & \\
\hline & Transportation & $7(1.9)$ & $2(8.0)$ & $5(2.1)$ & $0(0.0)$ & & \\
\hline & Others $^{\S}$ & $86(23.7)$ & $8(32.0)$ & $58(24.8)$ & $20(19.2)$ & & \\
\hline \multirow{4}{*}{$\begin{array}{l}\text { Frequency of } \\
\text { contact }\end{array}$} & Daily or almost daily & $232(63.9)$ & $11(44.0)$ & $155(66.2)$ & $66(63.5)$ & \multirow[t]{4}{*}{$18.46^{\dagger}$} & \multirow[t]{4}{*}{.005} \\
\hline & 1-2 times/week & $54(14.9)$ & $7(28.0)$ & $32(13.7)$ & $15(14.4)$ & & \\
\hline & 1-2 times/month & 37 (10.2) & $6(24.0)$ & $26(11.1)$ & $5(4.8)$ & & \\
\hline & Never met before & $40(11.0)$ & $1(4.0)$ & $21(9.0)$ & $18(17.3)$ & & \\
\hline
\end{tabular}

${ }^{*}$ Contacts $\mathrm{n} ;{ }^{\dagger}$ When a 24-hour contact log was completed on weekends or public holidays (childcare center is closed) or when the parent was off-duty, the contact log was not observed for the childcare center; ${ }^{中}$ Calculated by Fisher's exact test; ${ }^{\S}$ Hospital, kids' cafe, playground, etc.

(37.6\%) and children aged above 60 months and below 84 months (48.1\%). The most common frequency of contact was daily or almost daily in all age groups (Table 2).

In the scatterplot for ages of the children and their contacts, children aged 50-60 months had the highest number of physical and non-physical contacts, and the age of the contacts ranged widely, from other children to elderly individuals in their 80s (Figure 1).

\section{3) Features of children's contacts}

The type of contacts varied according to their duration, location, and frequency $(p<.001)$ (Figure 2-A, Figure 2-B, and Figure 2-C). The type of contact was physical in $100 \%$ and $88.0 \%$ of contacts with durations of $>4$ hours and $1-4$ hours, respectively; these proportions were higher than those found for other durations (Figure 2-A), and physical contact was found for $98.0 \%$ and $76.5 \%$ of contacts in the home and at educational institutions (private academies), respectively, which was likewise higher than was found for other locations (Figure 2-B). Physical contact also accounted for $67.2 \%$ and $73.0 \%$ of con- tacts with daily or almost daily frequency and 1-2 times a month frequency, respectively; these proportions were higher than those reported for other frequencies (Figure 2-C).

The duration of contacts differed according to their location and frequency $(p<.001)$ ((Figure 2-D and Figure 2-E). The location of contact showed varying distributions, with the highest percentages of contacts in the home being $>4$ hours in duration and contacts in transport or other locations being $<5$ minutes in duration (Figure 2-D). Further, the percentage of contacts $>4$ hours in duration was the highest $(19.0 \%)$ for contacts of daily or almost daily frequency. In contrast, the duration of $<5$ minutes was most common $(70.0 \%)$ for the "never met before" group (Figure 2-E).

The frequency of contacts differed according to their location. Specifically, the percentage of contacts with "daily or almost daily" frequency was $80.6 \%$ at home and $57.1 \%$ in transportation, which differed from those found for other locations $(p<.001)$ (Figure 2-F).

\section{Predictors of the Children's Number of Contacts}


In a multiple regression analysis containing variables that were significant in the univariate analysis (residential area, housing type, day of week, number of cohabitants) and age (in months), an important characteristic of child development, the final multivariable model with the number of cohabitants removed was constructed with a multiple stepwise variable selection algorithms. The day of the week was identified as a

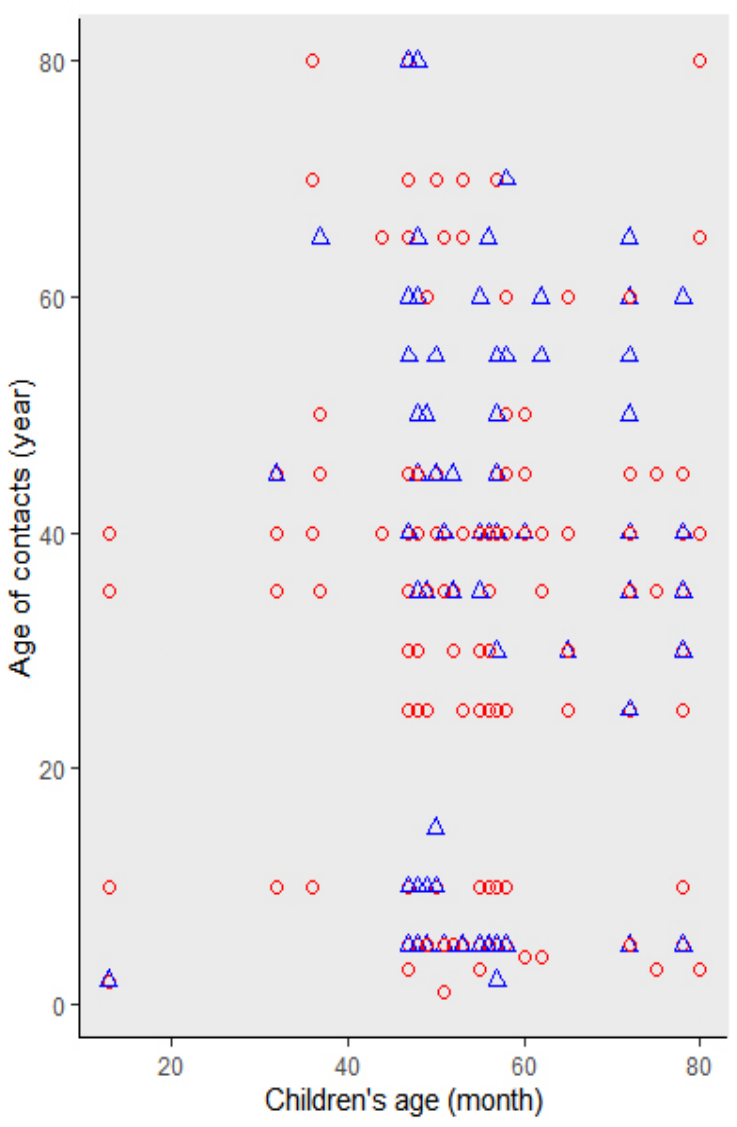

Figure 1. Scatter plot between children's ages and the ages of contacts. Scatter-plots of the children and their contacts showed assortative mixing of children with other children in their age groups and people in their 30-40s and 60-70s; O, physical contact; $\Delta$, non-physical contact. significant predictor of the number of contacts, and the total number of contacts was higher on weekdays than on weekends $(B=10.64, p=.010)$ (Table 3).

\section{DISCUSSION}

This was the first study that examined children's social contact patterns in Korea using the Social Contact Survey Instrument. The 30 participating children were in contact with an average of $12.1 \pm 9.1$ persons per child during the 24-hour period, ranging from 2 to 38 persons. This is higher than the averages of 10 persons reported in a Taiwanese study $(<5$ years of age) [22], 7.65 persons in a Hong Kong study (1-10 years of age) [6], 10.21 persons in an EU study (0-4 years of age) [1], and 8.64 persons in a French study ( $0-4$ years of age) [7]. The number of contacts was 5.3, 11.2, and 15.7 in the groups of children who were 13-36 months and above 36 months and below 60 months and above 60 months and below 84 months old, respectively. On the other hand, these findings were lower than those of Japanese study [11], which reported 9.8 and 19.2 contacts in the age groups of $0-2$ years and 3-5 years, respectively. Nevertheless, these results can be used only as a reference, and direct comparisons are inappropriate because previous studies used different age groups and age classifications [1,6,7,11,22]; nonetheless, it appears that Korean children have more contacts than those from other countries. This may be related to the popularity of various types of early education in Korea.

Univariate analysis showed that the number of daily contacts of children residing in Gyeonggi Province was significantly higher than that of children residing in Seoul. The children residing in Gyeonggi Province lived in a new city of large-scale apartment complexes with a middle-class population. Two childcare centers were located in Seoul. One was located in the central Gangnam area with population with a higher socioeconomic status, and the other was located in a more aging area, in Gangbuk. The childcare centers in Seoul were older than that in Gyeonggi Province. Therefore, the differences observed between Gyeonggi Province and Seoul may

Table 3. Factors Related to the Number of Contacts of Children

\begin{tabular}{|c|c|c|c|c|c|c|c|}
\hline Model & $\mathrm{B}$ & SE & $\beta$ & $\mathrm{t}$ & $p$ & Tolerance & VIF \\
\hline Age of children (ref. $>48$ months) & 3.25 & 2.63 & .17 & 1.24 & .227 & .95 & 1.05 \\
\hline Residential area (ref. Gyeonggi Province) & 2.79 & 3.59 & .16 & 0.79 & .439 & .46 & 2.17 \\
\hline Housing type (ref. apartment) & 0.27 & 3.40 & .01 & 0.08 & .938 & .65 & 1.55 \\
\hline Day of the week (ref. weekend) & 10.64 & 3.05 & .59 & 0.50 & .010 & .63 & 1.59 \\
\hline
\end{tabular}

*Stepwise multiple linear regression; ref., reference group; VIF, variance inflation factor. 
(A)

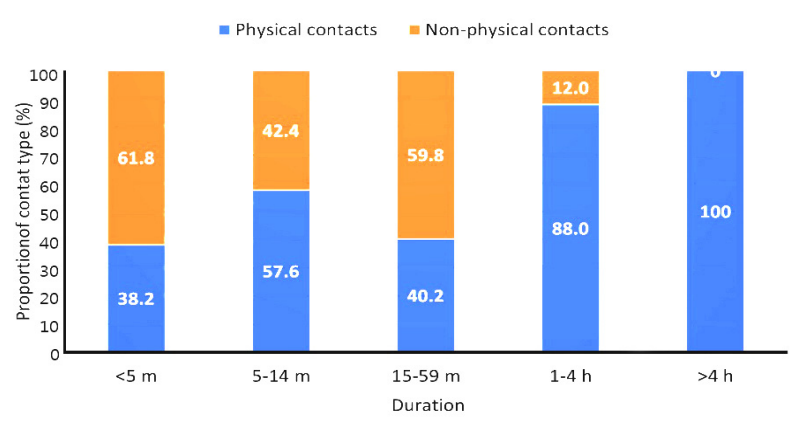

(C)

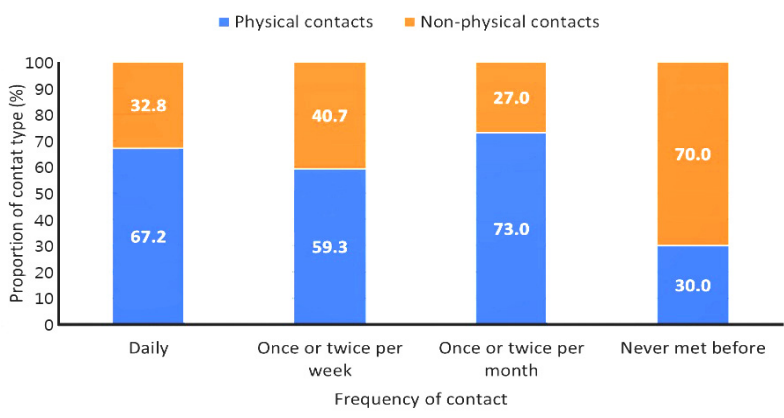

(E)

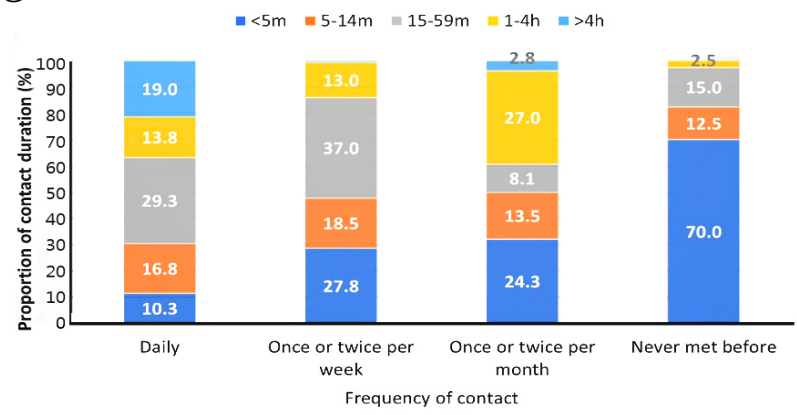

(B)

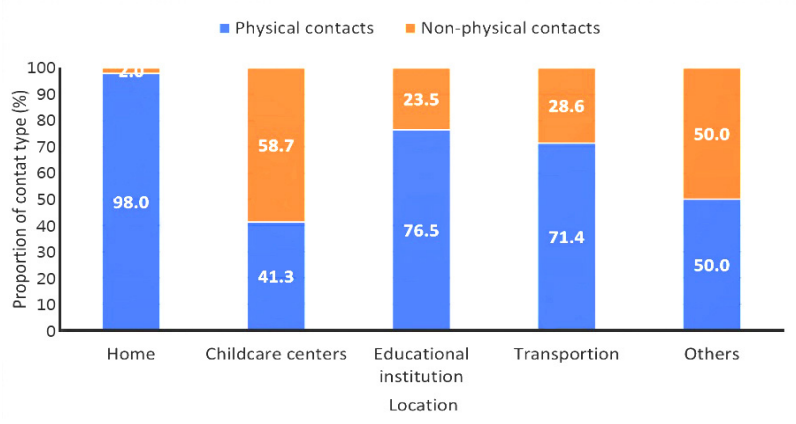

(D)

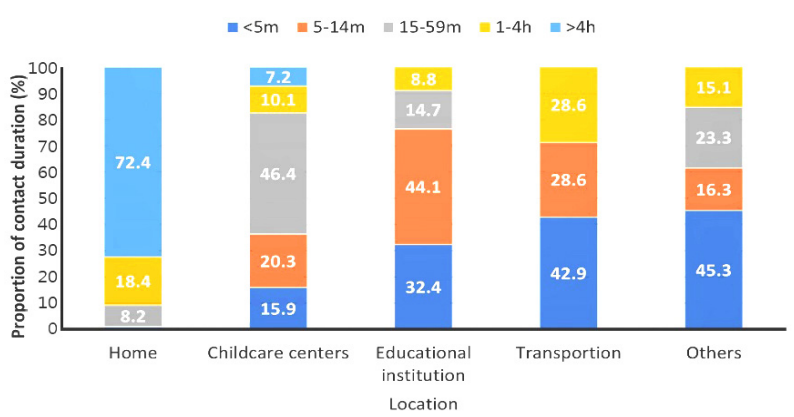

(

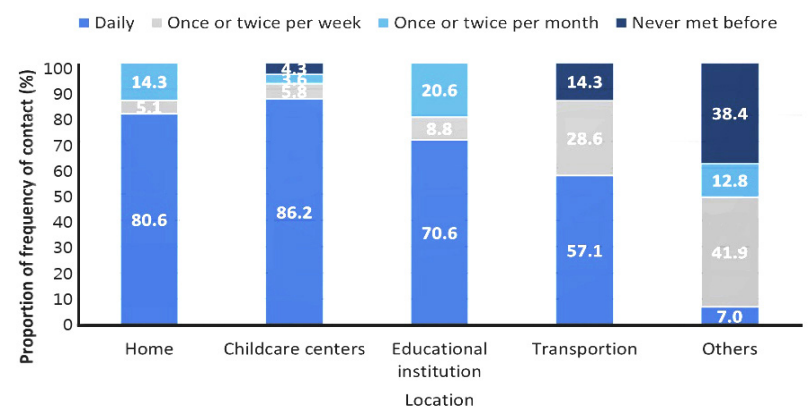

Figure 2. Contact patterns of the children in this pilot study. (A) Contact type by duration $\left(x^{2}=102.89, p<.001\right)$. (B) Contact type by location $\left(x^{2}=87.86, p<.001\right)$. (C) Contact type by frequency of contact $\left(x^{2}=22.23, p<.001\right)$. (D) Contact duration by location $\left(x^{2}=276.72, p<.001\right)$. (E) Contact duraton by frequency of contact $\left(x^{2}=102.00, p<.001\right)$. (F) Contact frequency by location $\left(x^{2}=207.62, p<.001\right)$.

reflect the characteristics of the aging area of Gangbuk. However, in the final multiple regression model of this study, area of residence did not significantly influence children's social contacts.

In the present study, the number of contacts was higher for children with more family members, and was also higher on weekdays than on weekends, which is consistent with previous findings $[11,16]$. Although previous studies on adults revealed differences in the number of contacts according to income, occupation, and education level $[1,6,11]$, no significant differences were found in the number of children's contacts based on their parents' income, occupation, and education level.

The scatter plot illustrating the distribution of children's age and that of their contacts showed that children came into contact with people of varying ages, suggesting that they can transmit diseases to a wide range of people. Consistent with previous studies $[1,16,23]$, children may transmit an infection through contact with their peers and inter-generationally.

Regarding the features of contact according to age, children aged 13-36 months showed more frequent contacts with their family members at home and had physical contacts lasting $>4$ hours with people they met daily, which is consistent with previous findings [11,24]. Furthermore, children aged 36 
months or older (above 36 months and below 60 months) showed a higher frequency of contacts lasting 15-59 minutes as well as contact at childcare centers, which may be because older children (above 36 months and below 60 months) tend to engage in more activities outside their homes.

Regarding the type of contact, physical contact was more common when the duration of contact was long (1-4 hours, $>4$ hours), occurred at home, and with a frequency of once or twice per month, followed by daily or almost daily. Although these features are consistent with the findings of studies on adults' social contacts $[1,7,9,11]$, children showed a higher percentage of physical contacts in all conditions (duration, location, and frequency) than adults.

To summarize the social contact patterns of children, they come into contact with people of diverse age groups. They are quite likely to be exposed to infections via physical contact at home, with people they meet monthly and daily, and through prolonged contact of 1-4 hours and $>4$ hours. As older children are exposed to more frequent contacts at childcare centers or private academies, specific and systematic infection prevention measures tailored to these places need to be developed.

This study has some limitations as a pilot study. First, this study used convenience sampling of childcare centers in Seoul and Gyeonggi Province, where the researchers could easily access research participants. Therefore, it was not possible to ensure the homogeneity of the research participants. Second, the sample size of children was insufficient according to age. Nevertheless, this study provided evidence of social contact patterns among preschool children. In the future, these limitations should be considered when performing large-scale social contact studies of children.

\section{CONCLUSION}

While the findings of this pilot study have limited generalizability because only 30 children were examined, the study is highly significant as the first attempt to identify children's social contact patterns in Korea. Similar studies that examined the features of social contact reported significant findings from smaller samples of college students (29 or higher [25] or 28 or higher [26]). The significance of this study is that it examined social contact patterns in preschool children in Korea, who had never been studied in the previous literature. Therefore, these findings provide the foundation for subsequent nationwide, large-scale studies. In addition to the current coronavirus disease 2019 (COVID-19) pandemic, threats posed by novel infections are projected to continue in coming years [27], calling for further Korea-based studies on social contacts in children, who are considered to be at high risk for infections.

Researchers should conduct repeated and large-scale studies on social contacts in persons of various age groups to help develop strategies to prevent the social transmission of infections, particularly among children, who are a population at high risk for infections.

\section{Conflict of interest}

No existing or potential conflict of interest relevant to this article was reported.

\section{Data availability}

Please contact the corresponding author for data availability.

\section{Acknowledgements}

This study was supported by the research fund of the Korea Centers for Disease Control and Prevention as part of the "Study on the Contacts Patterns of High-Risk Groups of Infections (Children and Elderly)" project, 2018. The authors would like to thank Professor Park HJ, who helped tremendously in analyzing the data for this project.

\section{REFERENCES}

1. Mossong J, Hens N, Jit M, Beutels P, Auranen K, Mikolajczyk R, et al. Social contacts and mixing patterns relevant to the spread of infectious diseases. PLoS Medicine. 2008;5(3):e74.

https://doi.org/10.1371/journal.pmed.0050074

2. Korea Disease Control and Prevention Agency. Middle East Respiratory Syndrome(MERS) [Internet]. Cheongju-si: Korean Center for Disease Control and Prevention; 2018 [cited 2020 August 16]. Available from:

http://www.cdc.go.kr/contents.es?mid=a30329000000

3. Oh MD, Park WB, Park SW, Choe PG, Bang JH, Song KH, et al. Middle East respiratory syndrome: What we learned from the 2015 outbreak in the Republic of Korea. Korean Journal of Internal Medicine. 2018;33(2):233-246.

https://doi.org/10.3904/kjim.2018.031

4. King James. Leviticus [Internet]. Washington D.C: U.S. Congress; 2007. Chapter 13, The Lawes and tokens wheareby the Priest is to be guided in discerning the Leprosie; [cited 2020 October 6]. Available from:

https://www.kingjamesbibleonline.org/1611_Leviticus-Chapter$13 /$

5. Roos D. Social distancing and quarantine were used in medieval times to fight the black death [Internet]. New York, NY: History Stories; 2020 [cited 2020 April 29]. Available from: 
https://www.history.com/news/quarantine-black-death-medieval

6. Leung K, Jit M, Lau EH, Wu JT. Social contact patterns relevant to the spread of respiratory infectious diseases in Hong Kong. Scientific Reports. 2017;7(1):7974. https://doi.org/10.1038/s41598-017-08241-1

7. Beraud G, Kazmercziak S, Beutels P, Levy-Bruhl D, Lenne X, Mielcarek N, et al. The French connection: The first large population-based contact survey in France relevant for the spread of infectious diseases. PLoS One. 2015;10(7):e0133203.

https://doi.org/10.1371/journal.pone.0133203

8. Melegaro A, Jit M, Gay N, Zagheni E, Edmunds WJ. What types of contacts are important for the spread of infections? Using contact survey data to explore European mixing patterns. Epidemics. 2011; 3(3-4):143-151. https://doi.org/10.1016/j.epidem.2011.04.001

9. Kretzschmar M, Mikolajczyk RT. Contact profiles in eight European countries and implications for modelling the spread of airborne infectious diseases. PLoS One. 2009;4(6):e5931 https://doi.org/10.1371/journal.pone.0005931

10. Ajelli M, Litvinova M. Estimating contact patterns relevant to the spread of infectious diseases in Russia. Journal of Theoretical Biology. 2017;419:1-7. https://doi.org/10.1016/j.jtbi.2017.01.041

11. Ibuka Y, Ohkusa Y, Sugawara T, Chapman GB, Yamin D, Atkins $\mathrm{KE}$, et al. Social contacts, vaccination decisions and influenza in Japan. Journal of Epidemiology Community Health. 2016;70(2): 162-167. https://doi.org/10.1136/jech-2015-205777

12. Hon KL, Leung KKY, Leung AK, Sridhar S, Qian S, Lee SL, et al. Overview: The history and pediatric perspectives of severe acute respiratory syndromes: Novel or just like SARS. Pediatric Pulmonology. 2020;55(7):1584-1591. https://doi.org/10.1002/ppul.24810

13. Zhai S, Ma Y, Gao Z, He J. Development of interactive biological motion perception in preschoolers and its relation to social competence. Social Development. 2020;29(2):564-577. https://doi.org/10.1111/sode.12414

14. McCall RB, Groark CJ, Hawk BN, Julian MM, Merz EC, Rosas JM, et al. Early caregiver-child interaction and children's development: Lessons from the St. Petersburg-USA orphanage intervention research project. Clinical Child and Family Psychology Review. 2019; 22(2):208-224. https://doi.org/10.1007/s10567-018-0270-9

15. Kiti MC, Kinyanjui TM, Koech DC, Munywoki PK, Medley GF, Nokes DJ. Quantifying age-related rates of social contact using diaries in a rural coastal population of Kenya. PLoS One. 2014;9(8): e104786. https://doi.org/10.1371/journal.pone.0104786

16. Read JM, Lessler J, Riley S, Wang S, Tan LJ, Kwok KO, et al. Social mixing patterns in rural and urban areas of southern China. Proceedings Blogical Sciences. 2014;281(1785):20140268. https://doi.org/10.1098/rspb.2014.0268
17. Oh HS, Ryu M, Park H, Yang Y, Jeong S. Study of the contacts patterns of high-risk groups of infections (children and elderly). Survey Report. Cheongju: Korea Centers for Disease Control and Prevention; 2019. Report No.: 11-1352159-001226-01.

18. Oh HS, Yang Y, Ryu M. Development of a social contact survey instrument relevant to the spread of infectious disease and its application in a pilot study among Korean adults. Journal of Preventive Medicine and Public Health. 2020;53(2):106-116. https://doi.org/10.3961/jpmph.19.251

19. Lawshe $\mathrm{CH}$. A quantitative approach to content validity. Personnel Psychology. 1975;28(4):563-575.

20. R Core Team. R: A language and environment for statistical computing [Internet]. Vienna: R Foundation for Statistical Computing; 2017 [cited 2019 Februray 14]. Available from: https://www.r-project.org

21. Warnes GR, Bolker B, Bonebakker L, Gentleman R, Huber W, Liaw A, et al. gplots: Various R programming tools for plotting data: $\mathrm{R}$ package version 3.0.1.1. [Internet]. Vienna: CRAN-R Project; 2019 [cited 2019 Februray 14]. Available from: https://CRAN.R-project.org/package=gplots

22. Fu YC, Wang DW, Chuang JH. Representative contact diaries for modeling the spread of infectious diseases in Taiwan. PLoS One. 2012;7(10):e45113. https://doi.org/10.1371/journal.pone.0045113

23. Munasinghe L, Asai Y, Nishiura H. Quantifying heterogeneous contact patterns in Japan: A social contact survey. Theoretical Biology and Medical Modelling. 2019;16(1):6. https://doi.org/10.1186/s12976-019-0102-8

24. Grijalva CG, Goeyvaerts N, Verastegui H, Edwards KM, Gil AI, Lanata $\mathrm{CF}$, et al. A household-based study of contact networks relevant for the spread of infectious diseases in the highlands of Peru. PloS One. 2015;10(3):e0118457. https://doi.org/10.1371/journal.pone.0118457

25. Edmunds WJ, Kafatos G, Wallinga J, Mossong JR. Mixing patterns and the spread of close-contact infectious diseases. Emerging Themes in Epidemiology. 2006;3:10. https://doi.org/10.1186/1742-7622-3-10

26. Mikolajczyk RT, Kretzschmar M. Collecting social contact data in the context of disease transmission: Prospective and retrospective study designs. Social Networks. 2008;30(2):127-135.

https://doi.org/10.1016/j.socnet.2007.09.002

27. World Health Organization. Coronavirus disease (COVID-19) advice for the public [Internet]. Geneva: World Health Organization; 2020 [cited 2020 April 29]. Available from:

https://www.who.int/emergencies/diseases/novel-coronavirus -2019/advice-for-public 